
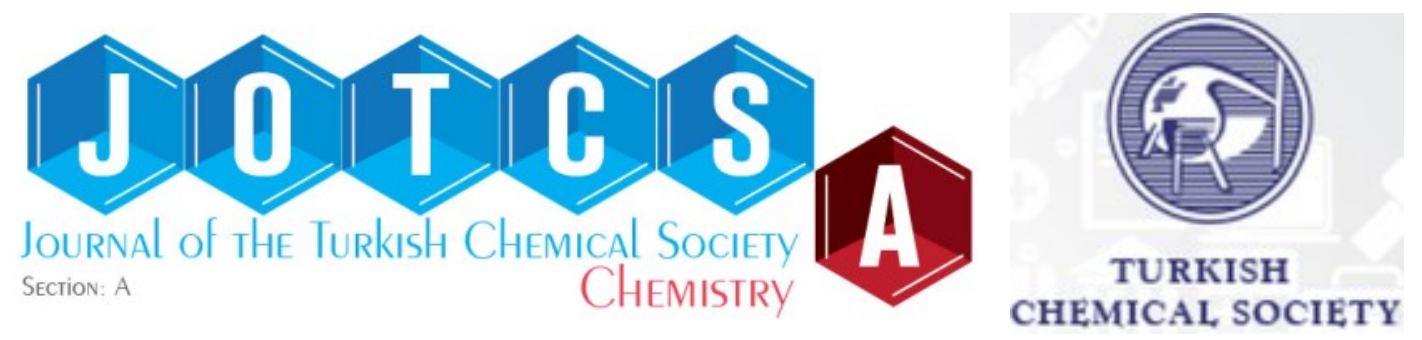

\title{
Synthesis of Reactive Polyurethane Adhesives and Studying the Effect of Ketonic Resins
}

\author{
Nesrin Köken ${ }^{1 *}$ D , Serdar Aydın² \\ ${ }^{1 *}$ Istanbul Technical University, Faculty of Science, Department of Chemistry, 34469-Maslak, Istanbul, \\ Turkey \\ ${ }^{2}$ Istanbul Technical University, Graduate School of Science, Engineering and Technology, Polymer \\ Science and Technology Department, 34469-Maslak, Istanbul, Turkey
}

Abstract: In this study, the effects of cyclohexanone formaldehyde ketonic resin (CFR) with different montmorillonite (MM) content (from 0,5 to 3 wt\%) on the viscosity, initial adhesion strength, and temperature resistance of polyurethane one-component adhesives were investigated. In situ MM modified cyclohexanone formaldehyde resin (MM-CFR) was used as polyol into formulation with a specified weight ratio (rate of $10 \%$ by weight of polyether polyol). One-shot technique was used for synthesis. CFR with varying montmorillonite (MM) content were incorporated blank polyurethane was synthesized using polyether polyol and polymeric 4,4'-methylene diphenyl diisocyanate ( $p-M D I)$. In experimental studies, the ratio of the isocyanate groups (NCO) to the hydroxyl group (OH) was 4.84 . Reaction completion was followed by FTIR spectroscopy. Chloroparaffin was used as a plasticizer to adjust the viscosity and to reduce the fragile structure of the product. The NCO \% values of the synthesized adhesive PU were measured by titration. When TGA data were examined, it was found that the heat resistance of the product increased with the addition of CFR and MM-CFR. As a result, it has been determined that the adhesion properties and thermal resistance were improved with the use of ketonic resins in one component reactive adhesives.

Keywords: Polyurethane, ketonic resin, cyclohexanone-formaldehyde resin, adhesive, montmorillonite

Submitted: December 11, 2018. Accepted: October 03, 2019.

Cite this: Köken N, Aydın S. Synthesis of Reactive Polyurethane Adhesives and Studying the Effect of Ketonic Resins. JOTCSA. 2020;7(1):1-10.

DOI: https://doi.org/10.18596/jotcsa.495458.

*Corresponding author. E-mail: nesrin@itu.edu.tr.

\section{INTRODUCTION}

Polyurethanes were developed by Otto Bayer in 1937 , and became a success story that is now a billion-dollar business (1). They are produced as elastomers, foams, coatings, adhesives fibers, synthetic leathers and others. The polyurethane industry has shown significant growth over the last twenty years, this being particularly the case with adhesives. There are many different types of PU adhesives with increasing demand being due to the versatility of PU chemistry and the unique properties of polyurethanes $(2,3)$. These normally consist of polyol (polyester or polyether type), isocyanate and other additives. The properties of the polyurethane adhesives depend on the stoichiometric proportions and the types of isocyanates and polyols used. Nowadays, availability of different types of polyols in commercial sizes enables polyurethane adhesives which meet customer requirements (4-5). Typically, adhesives are grouped according to their chemistry (6), with formaldehyde (F) based adhesives representing the most important group. As reaction partners of formaldehyde, urea (UF), melamine (MF), phenol (PF), resorcinol 
(RF) and mixtures thereof (e.g. MUF, PRF) are involved. Besides formaldehyde-based polymers, adhesives using highly reactive isocyanates are applied in wood industry, e.g. polymeric diphenylmethane diisocyanate (pMDI), emulsion polymer isocyanates (EPI), or polyurethane (PUR) adhesives. The performance of a wood adhesive system is dependent on a wide range of variables, such as the surface smoothness of wood substrate, temperature, $\mathrm{pH}$, presence of wood extractives, and the amount of debris present which are related to the environment such as the level and rate of a change in both temperature and relative humidity (7). Adhesives based on urea formaldehyde and phenol formaldehyde are the major adhesives used for bonding wood, but some of these adhesives are very sensitive to hydrolysis, and stress scission (8-9).

The oldest types of one-component PU adhesives were based upon di- or triisocyanates that cured by reacting with active hydrogens on the surface of the substrate or moisture present in the air or substrate. One-component reactive polyurethane adhesives are prepared by reaction between monomeric or polymeric isocyanates and polyols (10). These systems offer the advantage of being one-package systems. Moisture cure systems are available based on isocyanates. The atmospheric moisture hydrolyzes isocyanate to generate the primary amines which immediately react with the isocynate groups to give urea linkages. The urea linkage is more stable and more moisture resistant than the urethane linkage (11-12). Onecomponent polyurethane adhesives have been come popular on the European market for the bonding of load-bearing timber components such as glued laminated timber products, finger-joints and I-beams. Their main advantages are a colorless glueline, easy application of a onecomponent adhesives and fast hardening within one to three hours without heat application (1314). The one-component reactive polyurethane adhesives subject to study are widely used especially in the furniture sector. One of the most important parameters affecting the productivity of the furniture producers is that the parts joined by bonding are waiting for long time and cannot be subjected to any processing during this period. In this case, the productivity of the production decreases. Ketonic resins are used as a resin in the ink and paint sector in an intensive adhesion. Many successful products that use ketonic resins in this direction are commercially and domestically available (15-16). However, their use in polyurethane adhesives has not been the subject to date due to the fact that ketonic resins are more difficult to access than polyols and the costs associated therewith are high.

Montmorillonite (MM) a layered silicate used widely to prepare polymer-clay nanocomposites, consists of two external silica tetrahedral sheets and a central octahedral sheet of alumina. The layers with high aspect ratio (about $1 \mathrm{~nm}$ thickness and $100 \mathrm{~nm}$ width and length) are stacked via weak dipolar force and form interlayer galleries which are generally occupied by cations (for example $\mathrm{Na}^{+}, \mathrm{Ca}^{2+}, \mathrm{Li}^{+}$) which can be easily substituted with organic cations via ion exchange reaction in water. The special structures of MM play important roles in improving mechanical, thermal and diffuse barrier properties of polymerlayered silicate nanocomposites (17-18).

The aim of this work is to use CFR and montmorillonite modified cyclohexanone formaldehyde resin as polyol for polyurethane one component adhesives. PU adhesives synthesized were monitored with their physical, mechanical, thermal and spectroscopic properties. When TGA data were examined, it was found that the heat resistance of the product increased with the addition of CFR and MM-CFR. As a result, it has been determined that the adhesion properties and thermal resistance were improved with the use of ketonic resins in one component reactive adhesives.

\section{MATERIALS AND METHODS}

\section{Materials and Instrumentation}

A commercially available polymeric methylene diphenylene isocyanate ( $p-M D I)$ with a product name Wannate ${ }^{\circledR}$ PM-200 and a polyether polyol with a commercial name Caradol ED56-200 (Shell Chemicals) were used as received from the commercial suppliers. The polyol is a polyoxypropylene glycol with 2,000 MW and $\mathrm{OHV}$ 56. $\mathrm{p}-\mathrm{MDI}$ is a dark brown liquid with a functionality between 2.6-2.7 containing some higher functionality isocyanates. The NCO \% of the $\mathrm{p}$-MDI is between $30.5-32.0$. The viscosity of $\mathrm{p}$-MDI is $150-250 \mathrm{mPa} . \mathrm{s}$ at $25^{\circ} \mathrm{C}$ which means that the material is liquid at room temperature. The chemical structure of $p-$ MDI is shown in Figure 1. 


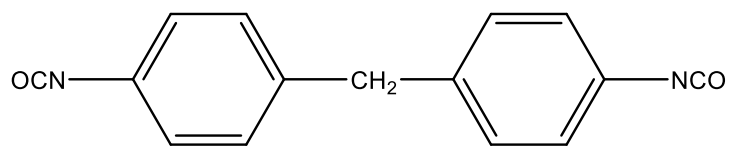

Pure 4.4' MDI,

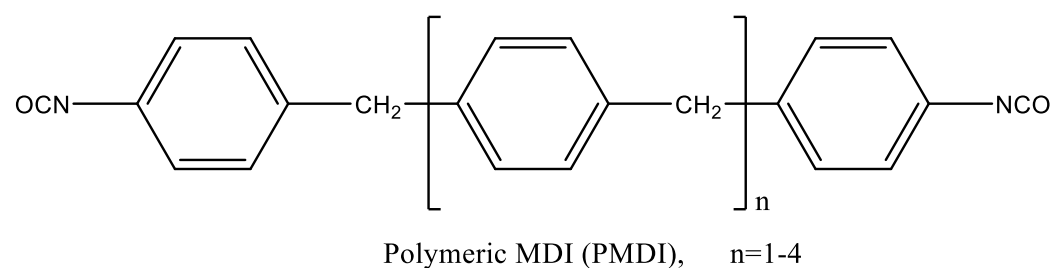

Figure 1: The chemical structure of MDI and p- MDI

Cyclohexanone- formaldehyde ketonic resin (CFR) and montmorillonite (MM) were used and the basic structure of the ketonic resin is shown in Figure 2.

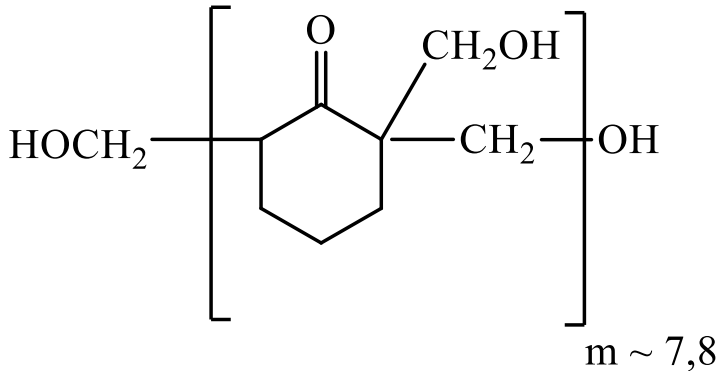

Figure 2: Cyclohexanone formaldehyde resin (CFR).

Montmorillonite is known as a clay and it is a 2:1 clay which means that it has two tetrahedral sheets of silica sandwiching a central octahedral sheet of alumina.

The chloroparaffin used in the synthesis is tris-(2chloroisopropyl) phosphate (TCPP) with a commercial name Fyrol-PCF avaliable from ICI Industrial Products. The basic structure of the TCPP is shown in Figure 3.<smiles>CC(Cl)COP(=O)(OC(C)CCl)OC(C)CCl</smiles>

Figure 3: Structure of Tris-(2chloroisopropyl) phosphate (TCPP).

The viscosity of the raw material is $65 \mathrm{mPa} . \mathrm{s}$ and the chlorine content is $32.5 \%$. The water content of the material is below $0.07 \%$. 2,2'dimorpholino diethyl ether (DMDEE) was used as a catalyst.

Fourier transform infrared (FTIR) spectra were performed to follow the reaction completion with
Bruker Tensor-27. FT-IR was also used for incoming quality control of the raw materials including p-MDI, polyol and chloroparaffin. TGA/DSC-1 from Mettler Toledo was used to determine the heat stability of samples. In order to prepare TGA samples were dried at $100{ }^{\circ} \mathrm{C}$ for $3 \mathrm{~h}$. A $5 \mathrm{mg}$ powder sample of the product was subjected to TGA analysis, and heated at linear heating rate of $10^{\circ} \mathrm{C} / \mathrm{min}$.

The flow behavior and the viscosities of the samples were measured with rheometer MCR-102 from Anton Paar. Shear Rate is changed from 1 to $100 \mathrm{rpm}$ and the viscosity is measured at 25 ${ }^{\circ} \mathrm{C}$. Spindle: PP25, plate-plate was used.

The NCO \% of the pre-polymers were measured according to EN-ISO 11909 with an automatic titrator. The model of the automatic titrator is T50 from Mettler Toledo. Test specimens are prepared according to EN 204:2001 and tested with a static force testing equipment with model DVT.G21 from Devotrans. Shear strength of samples were also measured after $1 \mathrm{~h}$ to see the build-up of adhesion performance depend on time.

\section{Synthesis of One Component Polyurethane Adhesives}

Polyurethane adhesives are synthesized with oneshot technique. One-shot technique is the addition of all raw materials at once and letting reaction to completion. NCO \% is kept between 15-18 for a good shelf life and it is required to make calculations to achieve pre-determined NCO \%.

\section{Calculations}

It is required to calculate the amount of polyol and isocyanate to be reacted to be able to obtain the chemically stoichiometric equivalents. By changing the isocyanate index the theoretical stoichiometric amount of isocyanate can be adjusted depending on the desired polyurethane structure $(2,13)$.

Experiments were carried out with constant $\mathrm{NCO} / \mathrm{OH}$ ratio. $\mathrm{NCO} / \mathrm{OH}$ ratio is 5.38 for 
comparison samples and of 4.84 for experiments carried out. In the case of reactive polyurethane adhesives, excess isocyanate isocyanate ( $\mathrm{NCO} / \mathrm{OH}$ is well above 4 ) is preferred, in order to ensure the presence of reactive -NCO groups at the pre-polymer ends. The final NCO \% was expected to be 16.24 for comparison samples and vary for the experiments depend on the $\mathrm{OHv}$ of CFR and MM-CFR.

\section{Synthesis of blanks PU samples}

Polyether polyol $(39.80 \mathrm{~g})$ was introduced into reaction vessel at room temperature and the temperature was raised to $60^{\circ} \mathrm{C}$ under inert atmosphere. p-MDI $(55.10 \mathrm{~g})$ was added than and the reaction carried out for $3 \mathrm{~h}$ at the temperature of $60-65^{\circ} \mathrm{C}$. Completion of reaction was followed by FT-IR. There is a characteristic peak at $3400 \mathrm{~cm}^{-1}$ corresponding to $\mathrm{OH}$ group of polyols. The peak disappears with the completion of reaction. NCO groups of isocyanate reacts with $\mathrm{OH}$ groups of polyols to form urethane linkage. There are no more $\mathrm{OH}$ groups left as excess of isocyanate is used and all $\mathrm{OH}$ groups are consumed. System was cooled down to $40{ }^{\circ} \mathrm{C}$ to add the catalyst (DMDEE) $(0.30 \mathrm{~g})$ and the product was discharged to a bottle under nitrogen<smiles>CC(C)OC(C)CCC(C)(C)O</smiles>

Polyetherpolyol to carry the tests. If chloroform used in PU prepolymer than it is added together with polyol to the reaction vessel.

Synthesis of PU adesives with ketonic resins CFR /or MM-CFR (3.98 g) was added with chloroform into the reaction vessel at room temperature. Chloroform is used to dissolve the CFR and/or MM-CFR because it does not melt even over $100{ }^{\circ} \mathrm{C}$ without solvent. Polyether polyol (35.82 g) was charged as second ingredient, then the temperature was raised to 65 ${ }^{\circ} \mathrm{C}$ to remove water under vacuum. The system was kept at $65^{\circ} \mathrm{C}$ under vacuum for $1 \mathrm{~h}$ until the water trapped was removed from the system. The next step is the addition of p-MDI (55.10 g) for the polymerization and the reaction was continued for $3 \mathrm{~h}$. Completion of reaction was followed by FT-IR. System was cooled down to 40 ${ }^{\circ} \mathrm{C}$ to add the catalyst $(0.30 \mathrm{~g})$ and the product was discharged to a bottle under nitrogen to carry the tests. Chloroform $\left(\mathrm{CHCl}_{3}\right)$ was stripped-off from the adhesives synthesized by using vacuum before adding catalyst. Formation of PU-CFR is shown in Scheme 1.<smiles>CC(CO)(CO)C1CCCC(CO)(CO)C1=O</smiles>

CFR<smiles>[R11]c1ccc(CCc2ccc([N+](=O)[O-])cc2)cc1</smiles>

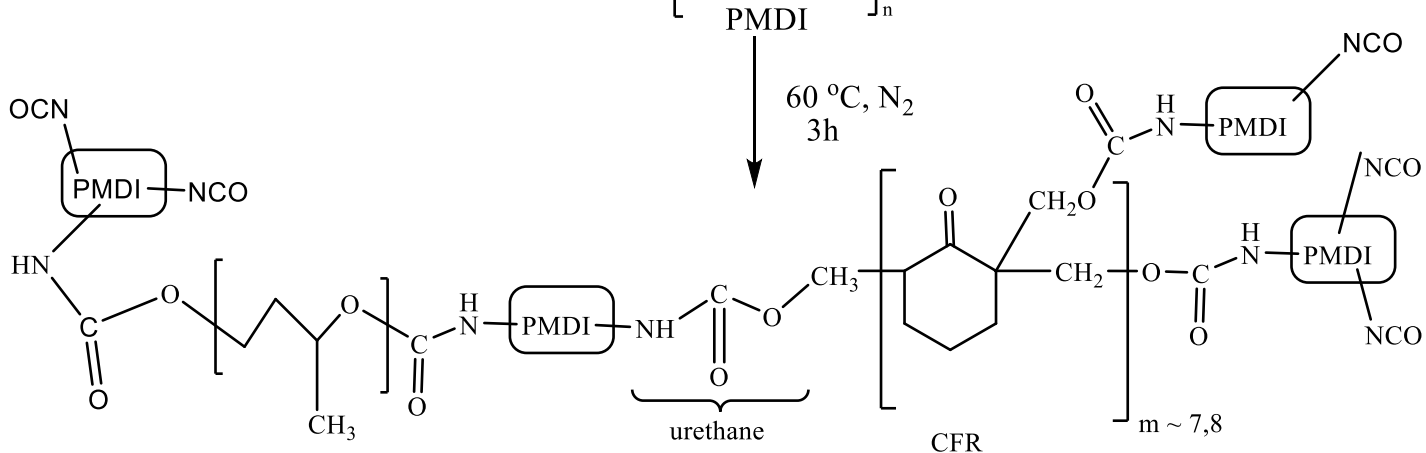

Scheme 1: Formation reaction of PU-CFR.

\section{RESULTS AND DISCUSSION}

Cyclohexanone-formaldehyde ketonic resin (CFR) and Montmorillonite containing Cyclohexanoneformaldehyde ketonic resin (MM-CFR) were synthesized in this study. Polyether polyol and polymeric 4,4'-methylene diphenyl diisocyanate (p-MDI) were used only to synthesize the polyurethane pre-polymer/adhesive blanks for comparision of results. CFR and MM-CFR at a rate of $10 \%$ by weight of polyether polyol were used in the synthesis. In the case of reactive polyurethane adhesives, excess isocyanate isocyanate ( $\mathrm{NCO} / \mathrm{OH}$ is well above 4$)$ is preferred, in order to ensure the presence of reactive -NCO groups at the pre-polymer ends (19). In parallel with the reduction of the amount of polyether polyol used, the ratio of isocyanate groups (NCO) to hydroxyl groups $(\mathrm{OH})$ was 5.38 (CFR and MMCFR ketonic resins were not involved in calculation). Chlorofom was used as a solvent in trials using ketonic resins. Chloroform was used as a solvent and removed by heat and vacuum after the reaction. The ratio of the isocyanate group (NCO) to the hydroxyl group $(\mathrm{OH})$ for the two different blank samples synthesized for this 
study (4.84). In the first case, chloroparaffin (TCPP) was used as a plasticizer in the first 6 synthesis to adjust the viscosity and to reduce the fragile structure of the products. The amount of montmorillonite used in the synthesis of polyurethane adhesive and other parameters are shown in Table 1 . The NCO \% values of the synthesized PU adhesives decreased with the use of CFR and MM-CFR. It has been found that the NCO \% value tends to decrease with the increase in the amount of MM in the CFR. The NCO \% value of the adhesives synthesized in the absence of chloroparaffin are higher as seen in Table 1 . It is known that chloroparaffin contains certain amount of water inside and if it is not removed than it will react with NCO groups of isocyanates. Sample PU1-CFR has a lower NCO \% than PU Blank-1 which results that OHv of CFR is higher than the polyether polyol used. It is expected from NCO \% to increase with increasing MM concentration but the opposite was observed. This could be explained as the $\mathrm{OH}$ groups that montmorillonite has and water trapped inside was not able to strip-off under vacuum reacted with isocyanate groups. Trapped water inside montmorillonite could be the major reason instead of $\mathrm{OH}$ groups available.

In order to characterize the chemical structure of CFR; MM (pristine clay), MM-CFR1, MM-CFR2, MM-CFR3 and MM-CFR4 samples were analyzed with FT-IR (Figure 3). Characteristic peaks of cyclohexanone formaldehyde resin appear at $3400 \mathrm{~cm}^{-1}, 2920 \mathrm{~cm}^{-1}, 1700 \mathrm{~cm}^{-1}$ and $1450 \mathrm{~cm}^{-1}$. In this study, these characteristic peaks were observed at $3399 \mathrm{~cm}^{-1}, 2925 \mathrm{~cm}^{-1}, 1699 \mathrm{~cm}^{-1}$, and $1445 \mathrm{~cm}^{-1}$. These peaks respectively attributed to hydroxy methyl groups, aliphatic $\mathrm{CH}_{2}$, carbonyl $\mathrm{C}=\mathrm{O}$, and $-\mathrm{CH}_{2}$ methylene bridges. Also, between $970-1200 \mathrm{~cm}^{-1}$ three main peaks were observed which belongs to the $\mathrm{C}-\mathrm{O}$ stretch between methylene bridges and cyclohexanone ring.

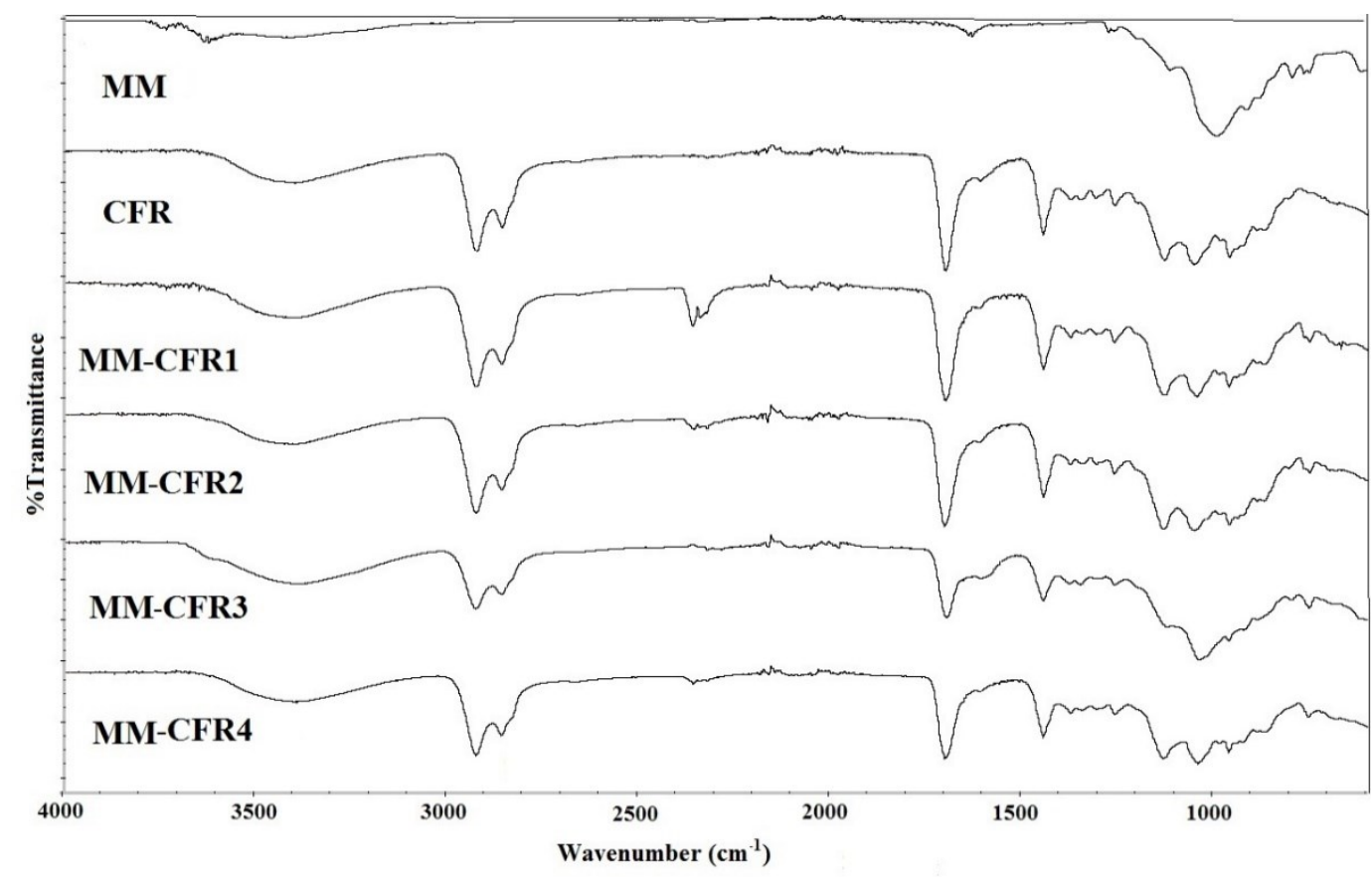

Figure 3: FTIR spectrum of pristine clay (MM), CFR and MM-CFRs.

Table 1: The amount of montmorillonite used in the synthesis of polyurethane adhesive and other parameters. $\left(\mathrm{T}=65^{\circ} \mathrm{C}\right)$.

\begin{tabular}{|c|c|c|c|c|c|c|}
\hline $\begin{array}{l}\text { Sample } \\
\text { Code }\end{array}$ & Ketonic & Resin & MM (w \%) & $\begin{array}{c}\begin{array}{c}\text { Chloroform } \\
\text { (Solvent) }\end{array} \\
\end{array}$ & $\begin{array}{l}\text { Chloroparaffin } \\
\text { (Plasticizer) }\end{array}$ & $\mathrm{NCO}$ \\
\hline PU1-Blank & & & - & - & + & 15.463 \\
\hline PU1-CFR & & CFR & - & + & + & 14.646 \\
\hline PU1-MMCFR1 & & MMCFR1 & 0.5 & + & + & 14.272 \\
\hline PU1-MMCFR2 & & MMCFR2 & 1.0 & + & + & 14.729 \\
\hline PU1-MMCFR3 & & MMCFR3 & 1.5 & + & + & 14.210 \\
\hline PU1-MMCFR4 & & MMCFR4 & 3.0 & + & + & 13.559 \\
\hline PU2-Blank & & - & - & - & - & 16.336 \\
\hline PU2-CFR-2 & & CFR & - & + & - & 15.328 \\
\hline PU2-MMCFR1 & & MMCFR1 & 0.5 & + & - & 15.166 \\
\hline PU2-MMCFR2 & & MMCFR2 & 1.0 & + & - & 15.745 \\
\hline
\end{tabular}

Each experiment was controlled with FT-IR to ensure the completion of reaction. FT-IR spectrum of polyol (Caradol ED 56-200) and PUMM-CFR2 were shown in Figure 4. The peak at 
$3428 \mathrm{~cm}^{-1}$ is due to stretching vibrations of $-\mathrm{OH}$ groups of polyol and CFR. Aliphatic $\mathrm{C}-\mathrm{H}$ vibrations are seen as peaks at $2800-2950 \mathrm{~cm}^{-1}$. The functional $-\mathrm{C}=\mathrm{O}$ group of cyclohexanone appears at $1700 \mathrm{~cm}^{-1}$. Broad $\mathrm{OH}$ peak of polyol must be lost and new urethane linkage should be formed if the reaction was completed. The stretching absorption of $-\mathrm{C}-\mathrm{N} 1405 \mathrm{~cm}^{-1}$ and the band 1701 $\mathrm{cm}^{-1}$ confirm the presence of $\mathrm{R}-\mathrm{O}-\mathrm{CO}-\mathrm{N}$ groups. The absorption bands around $2274 \mathrm{~cm}-1$ show the presences of terminal NCO groups in PU. The bands around $1217 \mathrm{~cm}-1$ and $1067 \mathrm{~cm}-1$ are due to $\mathrm{P}=\mathrm{O}$ and $\mathrm{P}-\mathrm{O}-\mathrm{C}$ stretching frequencies respectively. Furthermore, the $\mathrm{C}-\mathrm{Cl}$ stretching was seen at about $755 \mathrm{~cm}-1$.

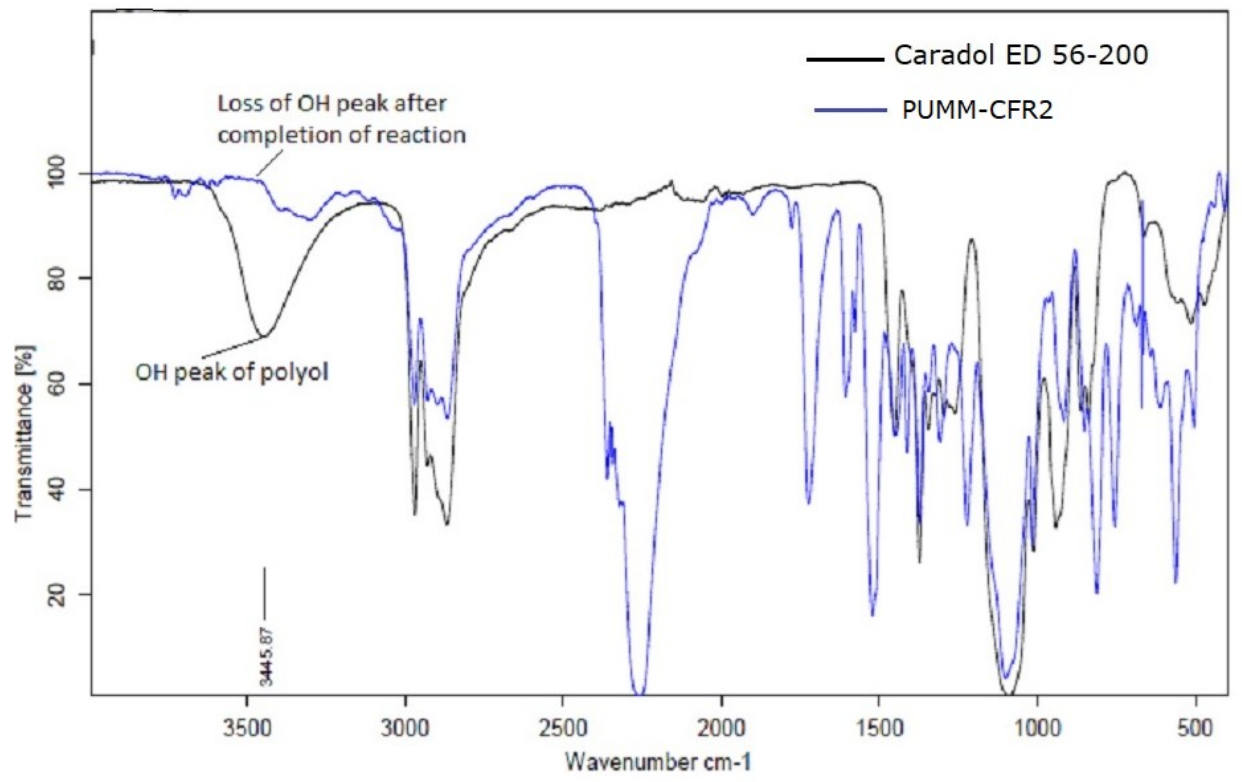

Figure 4: FT-IR spectrum of polyol (Caradol ED 56-200) and PU1-MMCFR2.

All PU adhesive synthesized with and without cyclohexanone- formaldeyde resins (CFR) containing different montmorillonite concentration show Newtonian flow properties. The viscosity of adhesives does not change with varying shear rate as can be seen from Figure 5 . Montmorillonite is a kind of filler which may give thixotropic behavior to materials but the amount used in CFR was not high so it didn't have any effect to change the flow properties of adhesives.

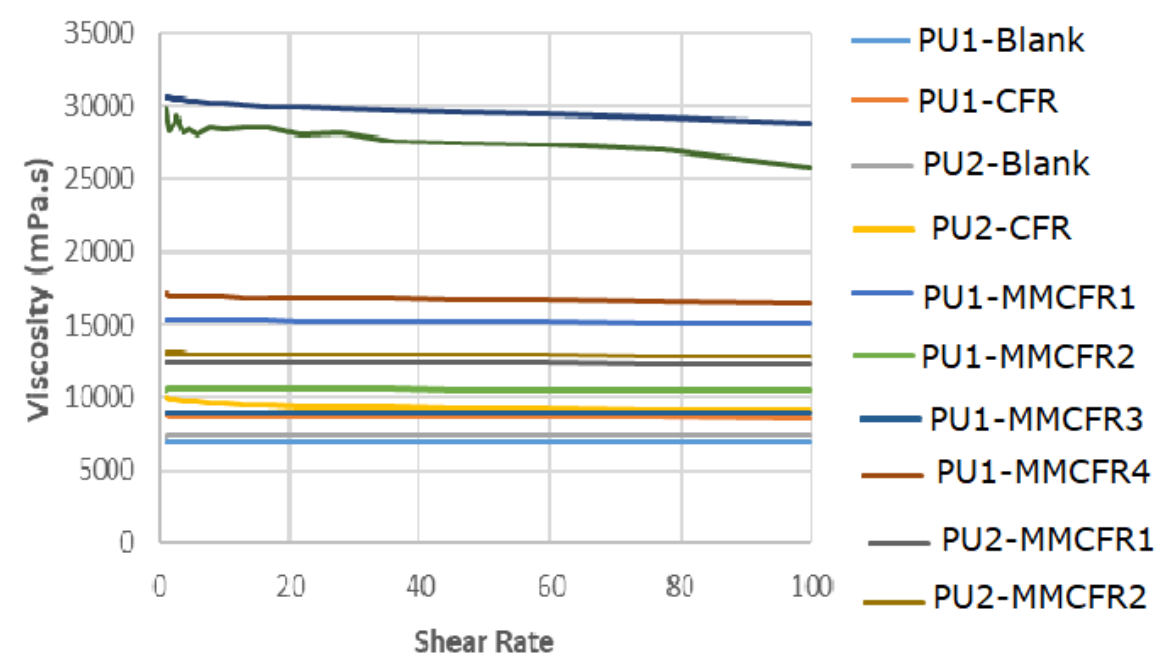

Figure 5: Viscosity (mPa.s) - Shear Rate (1/s) chart.

It was observed that the viscosity of the products increase in parallel with the increase of the MM content and CFR. This can be explained with OHv of CFR and also the increasing amount of montmorillonite content in CFR. Increasing amount of montmorillonite supports viscosity raise dramatically even used in small portions. Viscosity of adhesives increase from $\sim 7,000$ $\mathrm{mPa}$.s to $\sim 30,000 \mathrm{mPa}$.s without chloroparaffin (Figure 6). But the highest viscosity dropped down to $\sim 17,000 \mathrm{mPa}$.s which was still workable as an adhesive. The product viscosity remained at acceptable levels with incorporation of chloroparaffin.

Another reason of viscosity increase could be the water content of raw materials used. NCO groups of isocyanates would react with trace water in polyol mixture and it would cause NCO \% to decrease which result an increase of viscosity. 


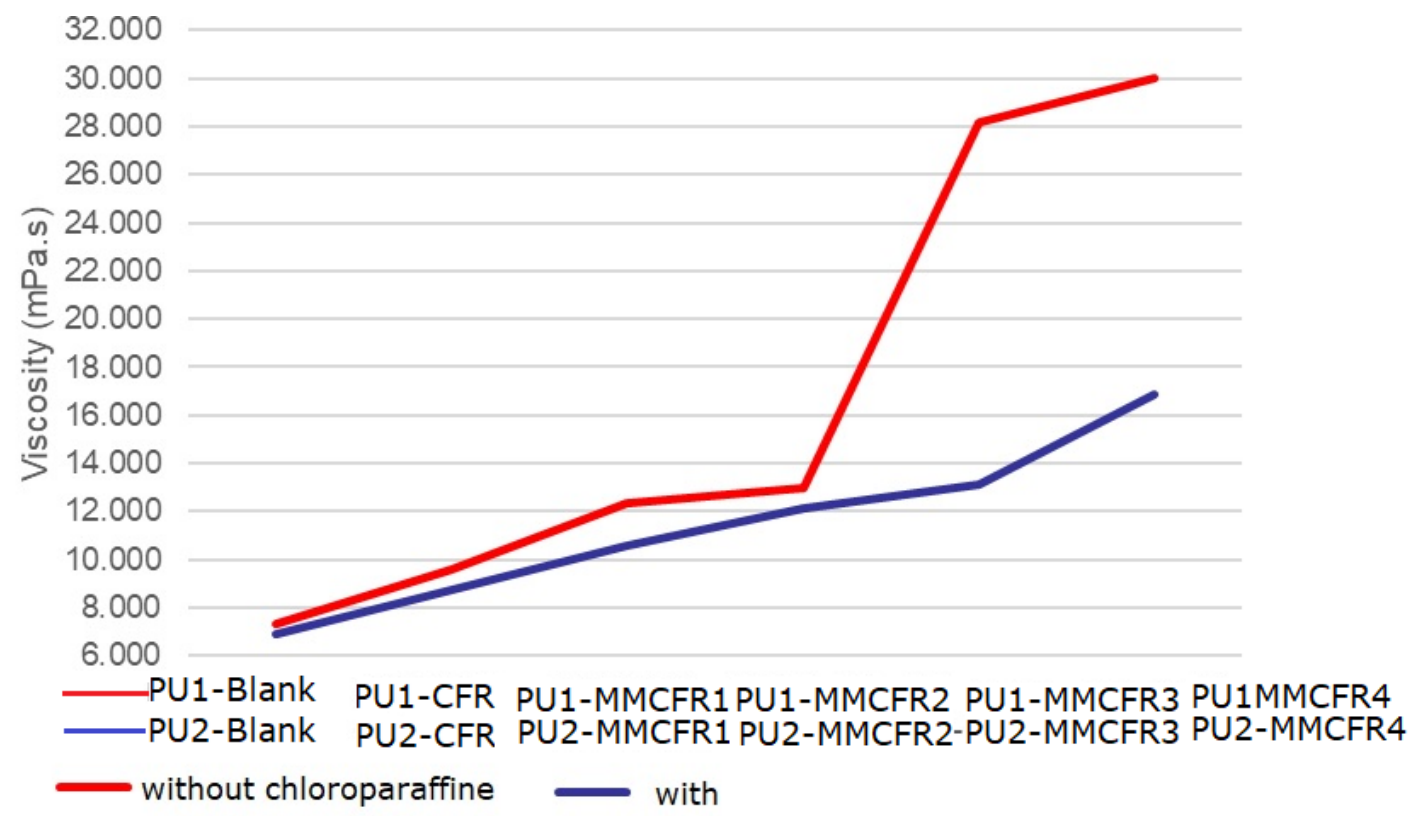

Figure 6: Viscosity change of adhesives with and without chloroparaffin.

Beach wood was used to measure the shear strength of adhesives. If adhesive layer detaches from the wood while loading to the equipment or any result could not be read from the equipment, it is considered "Fail". If fibers of the wood were come-off, after adhesive layer broken when stress applied at equipment than it is considered as "Wood Failure".

Blanks and adhesives prepared with PU-CFR and PU-MMCFR are far from showing any strength at time 10 min after bonding. Adhesives show raise in adhesion strength through time and datas can be collected at time 20 min after bonding. PU1CFR and PU2-CFR have higher shear strength than samples $\mathrm{Pu}$ Blank-1 and PU Blank-2 respectively at time 20 and 30 minutes after bonding. The results from Table 2 show us that PU-CFR and PU-MMCFR themselves have an influence on shear strength build-up through time. It was observed that the build-up of green strength and the final strength are both better than blank samples. After $24 \mathrm{~h}$ in other means 1440 minutes shear strength of each trial is high enough to result wood failure and there is not a significant difference.

Table 2: Shear Strength $\left(\mathrm{kgf} / \mathrm{cm}^{2}\right)$ at different intervals.

\begin{tabular}{|c|c|c|c|c|}
\hline Sample No & $\begin{array}{c}10 \text { min } \\
\left(\mathrm{kgf} / \mathrm{cm}^{2}\right)\end{array}$ & $\frac{20 \min }{\left(\mathrm{kgf} / \mathrm{cm}^{2}\right)}$ & $\frac{30 \text { min }}{\left(\mathrm{kgf} / \mathrm{cm}^{2}\right)}$ & $1440 \underset{\left(\mathrm{kgf} / \mathrm{cm}^{2}\right)}{\min (24 h)}$ \\
\hline PU Blank-1 & & 95.6 & 120.7 & \\
\hline PU1-CFR & & 105.8 & 155.3 & \\
\hline PU1-MMCFR1 & & Fail & 148.0 & \\
\hline PU1-MMCFR2 & & 125.7 & 184.0 & \\
\hline PU1-MMCFR3 & & 150.5 & 237,4 & \\
\hline PU1-MMCFR4 & & 164.3 & 202.5 & Wood Failure \\
\hline PU Blank-2 & Fail & 133.9 & 77.9 & \\
\hline PU2-CFR & & Fail & 177.0 & \\
\hline PU2-MMCFR1 & & 123.1 & 150.4 & \\
\hline PU2-MMCFR2 & & 165.3 & 178.1 & \\
\hline PU2-MMCFR3 & & 238.3 & 236.7 & \\
\hline PU2-MMCFR4 & & 245.7 & 243.5 & \\
\hline
\end{tabular}

Decomposition temperature of polyurethane adhesives synthesized were investigated with TGA. PU Blank-1 has the lowest decomposition temperature where the sample PU1-MMCFR4 has the highest decomposition temperature as shown in Figure 7. When TGA data were examined, it was found that the heat resistance of the product increased with the addition of CFR and MM-CFR.
It is found from the graph that samples with PUCFR and PU-MMCFR have a better high temperature resistance. The increase in the amount of MM in the CFR appears to have a positive effect on the results. In this case, the use of CFR and MM-CFR may be appropriate in applications where temperature resistance is required. 


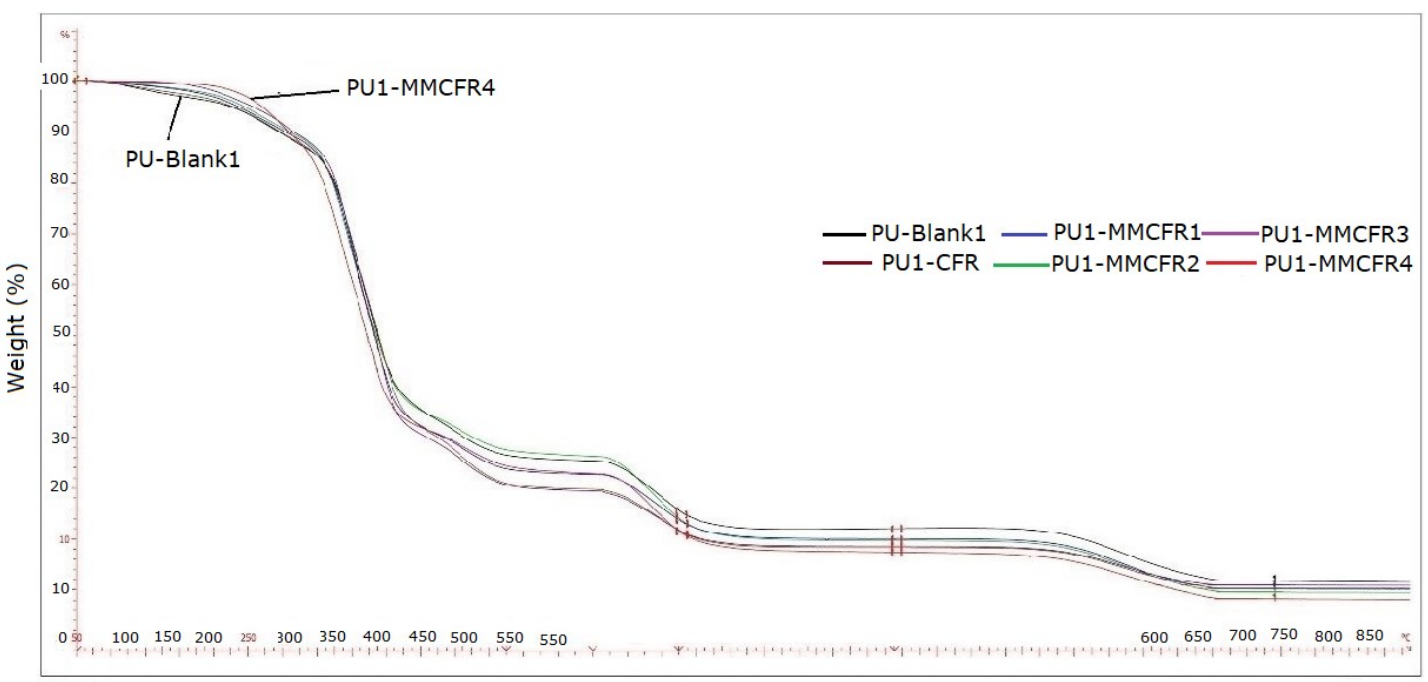

Temperature $\left({ }^{\circ} \mathrm{C}\right)$

Figure 7: TGA thermograms for PU Blank-1, PU1-CFR, PU1-MMCFR1, PU1-MMCFR2, PU1-MMCFR3 and PU1-MMCFR4.

Similar results were observed for the samples synthesized without chloroparaffin. PU Blank-2 has the lowest decomposition temperature where the PU2-MMCFR4 has the highest decomposition temperature as shown in Figure 8.

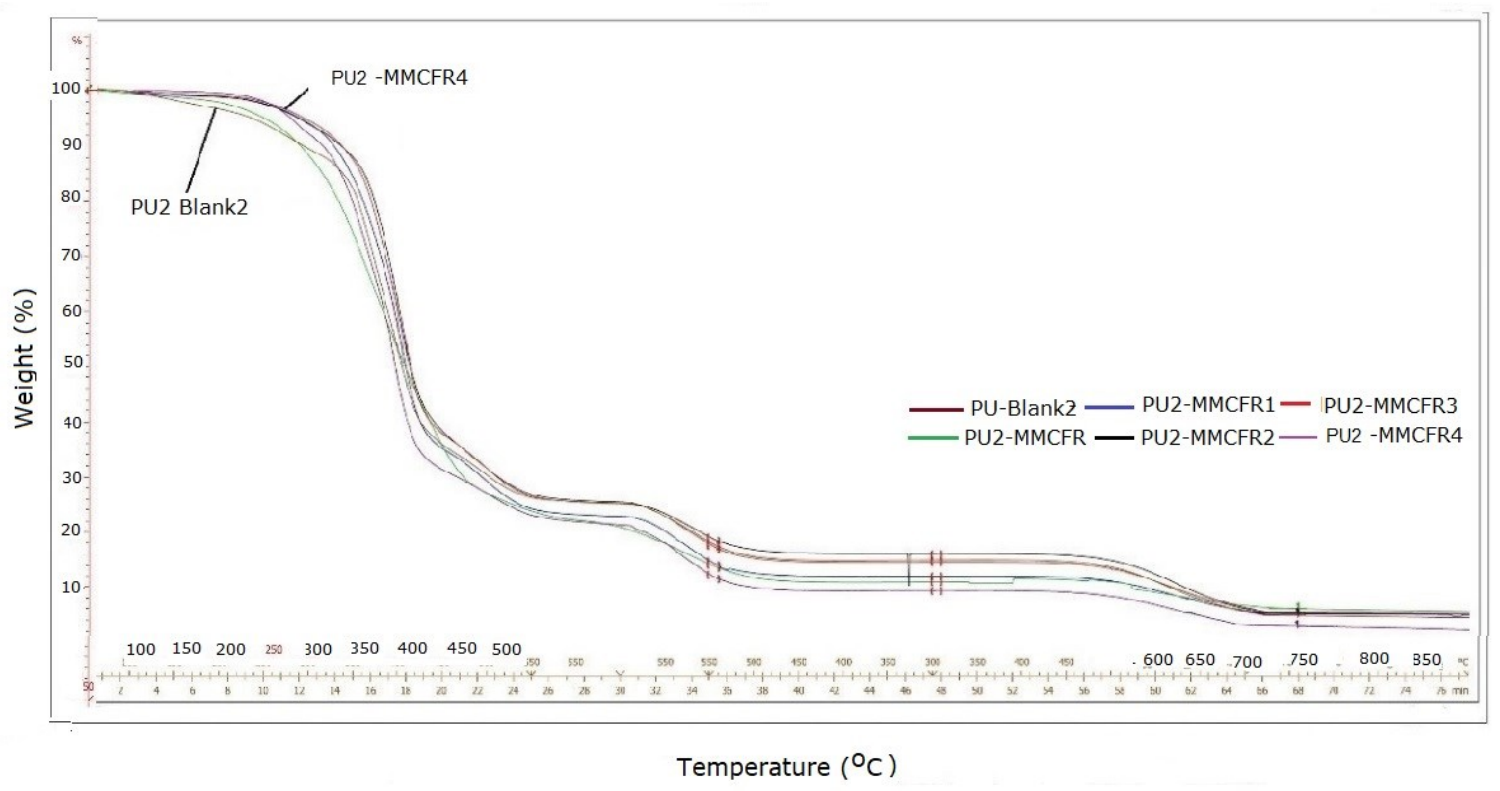

Figure 8: TGA thermograms for PU Blank-2, PU2-CFR and PU2-MMCFR1 to PU2-MMCFR4.

\section{CONCLUSION}

As a result of the study, it was observed that all products show Newtonian flow properties, so CFR does not have any effect on flow properties and the amount of montmorillonite is not high enough to give thixotropy. Viscosity increases with CFR and montmorillonite. Increasing viscosity value is also proportional with montmorillonite content in CFR. Viscosity increase is high enough not letting adhesives suitable for manual and machine applications. Chloroparaffin supports viscosity decrease without giving-up from other properties so it could be a good option to keep viscosity at certain value and letting to increase the montmorillonite content for better thermal and shear strength build-up in short time properties.

Use of CFR and montmorillonite in PU adhesives support adhesion strength growth which is also called green strength. No force values could be read at time 10 minute after bonding and it was an adhesive failure. Force values could be read at time 20 minute after bonding and specimens prepared with CFR showed higher shear strength. Samples prepared with CFR and montmorillonite had higher shear strength compared to CFR only samples. Higher content of montmorillonite resulted higher shear strength. Shear strength after $24 \mathrm{~h}$ or 1440 minute could not be read because the wood specimens are all broken. It 
can be judged that the adhesive and cohesive strength of adhesive are higher than the wood specimens' strength (13). Build-up of green strength can be also a result of lower free NCO content, so it might be the next step to keep free NCO content constant and change the amount of CFR and montmorillonite.

The NCO \% values of the synthesized PU adhesives were visibly reduced by the use cyclohexanone- formaldehyde resin. It can be judged that the OHv of the CFR was higher. Higher OHv will result lower NCO \% values of final product. Besides, NCO \% was not expected to decrease with increasing $M M$ amount in CFR. This can be explained by the water trapped in the MM and could not be removed by vacuum.

Samples with CFR showed higher thermal resistance and the highest thermal resistance was belong to the sample with highest montmorillonite content. This proves that thermal resistance increases with incorporation of CFR and montmorillonite.

Shear strength results show that the cyclohexanone formaldehyde ketonic resin and in situ modified montmorillonite cylohexanone formaldehy resins can be used as an important agent to increase the initial adhesion strength or build-up of green strength for one component reactive polyurethane adhesives with better thermal resistance.

\section{REFERENCES}

1. Saunders J, Frisch K. Polyurethanes: Chemistry and technology. Part 1. New York: Interscience Publishers; 1962.

2. Meier-Westhues U. Polyurethanes: coatings, adhesives and sealants. Vincentz Network GmbH; 2007.

3. Randall D, Lee $S$. The polyurethanes book. Everberg, Belgium: Huntsman Polyurethanes; 2002.

4. da Silva ALD, Martín-Martínez JM, Bordado JCM. Influence of the free isocyanate content in the adhesive properties of reactive trifunctional polyether urethane quasiprepolymers. International journal of adhesion and adhesives. $2006 ; 26(5): 355-62$.
5. Clauß S, Dijkstra DJ, Gabriel J, Kläusler O, Matner $M$, Meckel $W$, et al. Influence of the chemical structure of PUR prepolymers on thermal stability. International journal of adhesion and adhesives. 2011;31(6):513-23.

6. Frihart C. Wood adhesion and adhesives. New York: CRC Press; 2005.

7. Crocombe A. A.Single lap joint geometry. In: Da Silva L, Öchsner A, editors. Modeling of adhesively bonded joints. Springer; 2008.

8. Dunky M. Urea-formaldehyde (UF) adhesive resins for wood. International Journal of Adhesion and Adhesives. 1998;18(2):95-107.

9. Pizzi A, Mittal K. Wood adhesives. CRC Press; 2011.

10. Poljanšek I, Fabjan E, Moderc D, Kukanja $D$. The effect of free isocyanate content on properties of one component urethane adhesive. International Journal of Adhesion and Adhesives. 2014;51:87-94.

11. Uyanik N, Yalçinkaya H, Kizilcan N. Poly (dimethyl siloxane)-containing five-block copolymers: effects of resin blocks. Surface Coatings International Part B: Coatings Transactions. 2001;84(4):309-16.

12. Gruenewaelder B, Schoetmer B, Haller W, Ness B, Single-Component Polyurethane Adhesive United States Patent US 7,259,207 B2 Aug. 21, 2007

13. Frangi A, Fontana M, Mischler A, Shear behavior of bond lines in glued laminated timber beams at high temperatures. Wood Sci Technol (2004) 38: 119-126

14. Richter K, Pizzi A, Despres. Thermal stability of Structural One- Component Polyurethane Adhesives for Wood-StructureProperty Relationship. Journal of Applied Polymer Science. 2006;102:5698-5707

15. Kızılcan N, Ustamehmetoğlu B. Chemical polymerization of pyrrole in the presence of ketone-formaldehyde resins. Journal of Applied Polymer Science. 2005;96(3):618-24.

16. Uhl FM, Davuluri SP, Wong S-C, Webster DC. Polymer films possessing 
nanoreinforcements via organically modified layered silicate. Chemistry of materials. 2004;16(6):1135-42.

17. Chaiko DJ, Leyva AA. Thermal transitions and barrier properties of olefinic nanocomposites. Chemistry of materials. 2005;17(1):13-9.
18. Ionescu M. Chemistry and technology of polyols for polyurethanes. 2nd edition. Vol. 1. Shawbury, Shrewsbury, Shropshire, United Kingdom: Smithers Rapra; 2016.

19. F. Merger, G. Schleier and D. Schlotterbeck, Germ. Offen. DE $3,624,924(1988)$. 